\title{
The Most Frequent Causes of Hospitalization of Iranian Pilgrims in Iraq During a 5-Month Period in 2012, and Their Outcome
}

\author{
Soleiman Sadeghi, ${ }^{1}$ Ali Heidari, ${ }^{1}$ Hosein Fazli, ${ }^{1}$ Mashallah Rezaei, ${ }^{1, *}$ and Javad Sheikhzadeh ${ }^{1}$ \\ ${ }^{1}$ Hajj and Pilgrimage Medical Center, Iraq \\ *Corresponding Author: Mashallah Rezaei, Hajj and Pilgrimage Medical Center, Iraq. E-mail: rezaei@hmc.ir
}

Received 2013 June 11; Revised 2014 January 28; Accepted 2014 November 1.

\begin{abstract}
Background: Investigating the prevalence of diseases and causes of hospitalization of Iranian pilgrims in Iraq can be helpful for healthcare programmers in scheduling a healthy and joyful trip for pilgrims and reducing their mortality and morbidity.

Objectives: The main purpose of this study was to determine the frequency of Iranian pilgrims' referral cases to Karbala and Najaf hospitals in Iraq during a 5-month period in 2012.

Patients and Methods: In this cross-sectional study, medical records of all patients referred to Iraqi hospitals from Iranian clinics during a 5-month period from 16 January 2012 until 14 June 2012 was recorded. A checklist, including demographic data and diagnostic causes were prepared and completed by general practitioners. Then, the completed forms were checked and delivered to health surveillance supervisors.

Results: A total of 177 referral cases from Iranian clinics to Iraqi hospitals were recorded in 5 months. Most of these referrals were due to cardiovascular diseases with $38.6 \%$, then comes trauma with $26.55 \%$, and finally renal failure in need of dialysis with $12.43 \%$. About $80.2 \%$ of the patients were discharged, $13 \%$ of them were sent to Iran, and $6.2 \%$ died. Around $90 \%$ of deaths were due to heart diseases.

Conclusions: Considering the high prevalence of cardiovascular diseases and fractures in Iranian pilgrims, the necessity of self-care education to diminish such rates is substantial.
\end{abstract}

Keywords: Dialysis, Cardiovascular Diseases, Fracture, Trauma, Referral, Karbala, Najaf

\section{Background}

Karbala and Najaf cities are located in southwest of Baghdad, and constitutes the pivot of devotion for more than a hundred million Shi'a Muslims. Furthermore, during seasons of pilgrimage, millions of pilgrims from Iraq, Arab, and other foreign countries (more than 60 countries around the world) visit Karbala and Najaf. Millions of people from Iran go to Iraq, every year (1). These huge amount of travels, if not taken care properly, can carry a high risk for morbidity and mortality for the travelers (2). Few articles have discussed the epidemiology of travelling diseases in Iraq and there is no report about causes of mortality and incidence of hospitalization in Iraq. Registering of hospitalization data is the starting point of any study conducted on the prevention programs (3). Also, investigating the prevalence of diseases and hospitalizations in Iraq can be helpful for healthcare programmers. To provide a healthy and joyful trip for pilgrims and considering the high cost of patient care in Iraqi hospitals, it is necessary to investigate the patients' outcome during these religious trips (4).

\section{Objectives}

The main purpose of this study was to determine the frequency of referral cases to Karbala and Najaf hospitals in Iraq during a 5-month period in 2012.

\section{Patients and Methods}

In this cross-sectional study, the medical records of all Iranian patients who referred to Iraqi hospital from Iranian clinics during a 5-month period from 16 January 2012 until 14 June 2012 were reviewed. This research project was in consistent with the ethics codes of Research Ethics Committee. Also, personal information of the participants was kept confidential.

A checklist, including demographic data and medical records was prepared and completed by general practitioners. The questionnaires were anonymous and there were no ethical considerations. The physicians monitored the pilgrims' health status and recorded any occurrence of the diseases on a report sheet that were specially designed for the purposes. Validity of the record sheets were confirmed by some expert physicians and health managers, also the reliability of them were verified by performing a pilot study one year before starting the main study (During Hajj 2011). All Iranian patients' records in Iraqi hospitals due to referral from Iranian clin-

Copyright ( 2015, Iranian Red Crescent Medical Journal. This is an open-access article distributed under the terms of the Creative Commons Attribution-NonCommercial 4.0 International License (http://creativecommons.org/licenses/by-nc/4.0/) which permits copy and redistribute the material just in noncommercial usages, provided the original work is properly cited. 
ics during a 5-month period from 16 January 2012 until 14 June 2012 were selected and enrolled in this study by census sampling method and then were analyzed. The study was ethically approved by the Health Research Ethics Committee of the Hajj and Pilgrimage Center. Confidentiality of names of all the subjects was observed.

All records were studied in Hajj and Pilgrimage Health Research Center by a physician to ensure completeness of information and the discrepancies or defects were corrected by reviewing the records. Data were recorded in a spreadsheet (Excel software) and then after returning to Iran, the data were analyzed with SPSS software (version 16). Variables were described using frequencies and percentages or means and standard deviations.

\section{Results}

Totally, 177 cases during 5 months from 16 January 2012 until 14 June 2012 had been refereed to Iraqi hospitals. A total of $84(47 \%)$ patients were female. The median (STD) age of these patients was $56.23 \pm 21.04$ y between 1 and 93 years.

Average length of hospitalization was 2 days, between 1 and 9 days. Most of them were referred due to cardiovascular diseases and trauma (Figure 1). A total of 148 $(85.3 \%)$ patients were referred to hospitals in Karbala and $27(14.7 \%)$ of them to Najaf hospitals. Patients with metabolic diseases and in particular, diabetes mellitus had the highest and those with Ob/Gyn had the lowest average age (Table 1). Finally, 142 (80.2\%) patients were discharged and $23(13 \%)$ of them were sent to Iran and $6.2 \%$ died. About $90 \%$ of deaths were due to cardiovascular diseases. The mean age of the patients according to the cause of hospitalization are shown in Table 1.

Figure 1. Causes of Hospitalization of Iranian Pilgrims Referred to Iraqi Hospitals in Karbala and Najaf During Five Months in 2012

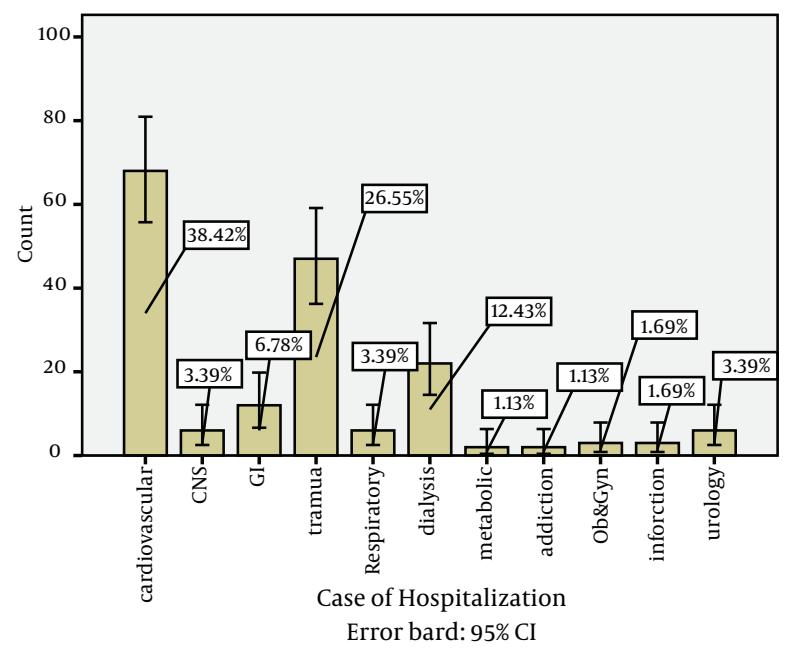

Error bars: $95 \% \mathrm{CI}$.
Table 1. Mean Age of Hospitalized Patients According to the Cause $^{\mathrm{a}}$

\begin{tabular}{lc}
\hline Cause of Hospitalization & Age, $\mathbf{y}$ \\
\hline Cardiovascular & $63.29 \pm 16.87$ \\
\hline CNS & $56.83 \pm 23.57$ \\
\hline GI & $43.50 \pm 26.44$ \\
\hline Trauma & $50.72 \pm 24.23$ \\
\hline Respiratory & $54.42 \pm 27.23$ \\
\hline Dialysis & $62.68 \pm 10.73$ \\
\hline Metabolic & $68.50 \pm 12.02$ \\
\hline Addiction & $61.00 \pm 12.73$ \\
\hline Ob/Gyn & $30.00 \pm 2.65$ \\
\hline Infection & $37.00 \pm 14.00$ \\
\hline Urology & $51.83 \pm 25.63$ \\
\hline
\end{tabular}

${ }^{\mathrm{a}}$ Data are presented as mean $\pm \mathrm{SD}$.

\section{Discussion}

This study is the first study about the causes of Iranian pilgrims' hospitalization in Iraqi hospitals. The results show that the majority of the hospitalized cases had cardiovascular, trauma, and renal failure in need of dialysis.

Few articles have discussed the epidemiology of travel diseases in Iraq, however, one study conducted on 877 Iranian patients in temporary clinics of Hajj and Pilgrimage organizations in Iraq showed that about $40 \%$ of the patients were referred for affliction of digestive complications, $21 \%$ for pulmonary disorders, and 15\% for cardiovascular disorders (2). Also, the deteriorating infectious disease situation in Iraq as outlined in the news item by WHO should be of international concern (5). However, in our study this rate was low.

Pilgrims with relatively old age and high prevalence of cardiovascular diseases are among the travelers. Changes in living conditions; environment and lifestyle; stress; fatigue; mental and physical incompliance with these conditions cause or aggravate cardiac events in such a trip. Also, discontinuation or irregular taking of medications is an important factor in these cases (6).

Trauma is the second leading cause of hospital admission of pilgrims in Iraq, which is caused by falling down in hotels, pathways, and holy places; elevator accidents in hotels; road accidents; and terrorism incidents.

Our study is a pilot one with some limitations. First, it highlights only those cases referred from Iranian clinics during a 5-month period. It is only a reflection of pilgrims' status. Pilgrims are somewhat careless about their health status, as they want to avail every single minute to perform rituals. However, they are forced to seek medical care when they feel sick (7).

This study will also serve as an aid for the Health Ministry of Iraq to take appropriate measures for effecting stricter regulations for the physical fitness of pilgrims 
and anticipating health services for them. It is recommended that health authorities of other countries should undertake counseling and medical testing of all persons planning for pilgrimage beforehand (at least 6 months earlier to the start of their journey) and arrange an orienting program to advise and educate pilgrims regarding the health care. It is also recommend to ban high risk cardiac patients from this trip unless they obtain acceptable medical permissions. Such patients should also possess a medical card; stating a brief record of their main problem and medications taken (generic names). This will reduce hospitalization and mortality rate and the burden on health services. Considering the high prevalence of cardiovascular diseases and fractures in Iranian pilgrims, the necessity of self-care education to diminish such rates is substantial.

\section{Acknowledgements}

The authors would like to acknowledge the Hajj and pilgrimage Medical Center.

\section{Footnote}

Authors' Contribution:Study concept and design: Soleiman Sadeghi; acquisition of data: Ali Heidari; analysis and interpretation of data: Hosein Fazli; drafting of the manuscript: Mashallah Rezaei; and critical revision of the manuscript for important intellectual content: Javad Sheikhzadeh.

Funding/Support:This study was supported by the Hajj and Pilgrimage Medical Center.

\section{References}

1. Bundhun R. Iraqi City's Religious Tourism Set to Grow. Iraq: The National; 2010. Available from: http://www.thenational.ae/business/travel-tourism/iraqi-citys-religious-tourism-set-to-grow.

2. Joneidi $\mathrm{H}$, Inanlou $\mathrm{M}$, editors. The ethologic investigation of admissions in Iranian clinics of Karbala and Najaf during a five month period in 2012.; International Medical Congress On Hajj and Pilgrimage.; 2012; Tehran, Iran. p. 23.

3. Al-Harthi AS, Al-Harbi M. Accidental injuries during muslim pilgrimage. Saudi Med J. 2001;22(6):523-5. [PubMed:11426245]

4. Al-Ghamdi SM, Akbar HO, Qari YA, Fathaldin OA, Al-Rashed RS. Pattern of admission to hospitals during muslim pilgrimage (Hajj). Saudi Med J. 2003;24(10):1073-6. [PubMed:14578971]

5. Dyer O. Infectious diseases increase in Iraq as public health service deteriorates. BMJ. 2004;329(7472):940. [PubMed: 15499110]

6. Sadegi S, Mortazavi SM, Salavatiha H. Abstracts of the 1th International Medical Congress On Hajj and Pilgrimage August 30th to September 1st.; International Medical Congress On Hajj and Pilgrimage.; Tehran, Iran. 2012.

7. Mortazavi M, Biranvand B, Shirafkan M, editors. Assessing Awareness, Insight and Performance of 2011.; International Medical Congress On Hajj and Pilgrimage.; 2012; Tehran. Tehran: p. 34. 